\title{
Exercise stress echocardiography with cardiac function parameters in the assessment of coronary microcirculation
}

\author{
(iD) Ana Fabris* \\ The Polyclinic for \\ cardiovascular diseases \\ and prevention Sveti Nikola, \\ Korčula, Croatia
}

KEYWORDS: exercise stress echocardiography, coronary microcirculation, cardiac function parameters. CITATION: Cardiol Croat. 2021;16(1-2):48. | https://doi.org/10.15836/ccar2021.48

*ADDRESS FOR CORRESPONDENCE: Ana Fabris, Poliklinika za kardiovaskularne bolesti i prevenciju Sveti Nikola, Strećica 6, HR-20260 Korčula, Croatia. / Phone: +385-98-1704343 / E-mail: fabrisana@yahoo.com ORCID: Ana Fabris, https://orcid.org/0000-0001-9588-6788

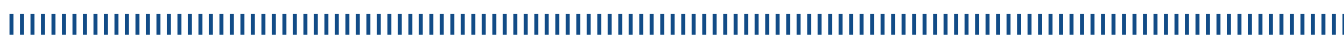

Introduction: Small coronary vessel disease may be related to a functional and/or organic factor Case report: A 60-year-old man with the history of the arterial hypertension and type 2 diabetes, presents to the Polyclinic with a significant number of VES and nsVT in the $24 \mathrm{~h}$ ECG monitoring. Slightly enlarged LV, moderately enlarged LA and mild MR are shown in the transthoracic echocardiography. Systolic and diastolic functions of the LV are found within normal limits. Exercise stress echocardiography with parameters of the cardiac function is interrupted at achieved $83 \%$ of the theoretical maximum frequency due to arrhythmia, without the ST depression. WMSI 1.25 is registered at the baseline and 1.13 immediate postpeak. Significant postpeak color Doppler derived strain rate decrease is registered in midanteroseptal, basal inferolateral and midinferior segment. Coronary angiogram reveals no organic stenosis of the main epicardial coronary arteries, but diffuse tightening of the lowest segments of the coronary macrocirculation, which might be related to the diffuse microvascular disease in diabetes and arterial hypertension.

Conclusion: Exercise stress echocardiography with the cardiac function parameters might be useful in detection of the small coronary vessel disease. ${ }^{1,2}$
RECEIVED:

December 4, 2020

ACCEPTED:

December 18, 2020

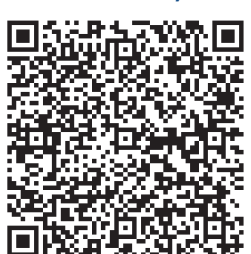

$\square$ Cardiologia Croatica 2021;16(1-2):48.
LITERATURE IIIIIIIIIIIIIIIIIIIIIIIIIIIIIIIIIIIIIIIIIIIIIIIIIIIIIIIIIIIIIIIIIIIIIIIIIIIIIIIIIIIIIIIIIIIIIIII

1. Hanekom L, Cho GY, Leano R, Jeffriess L, Marwick TH. Comparison of two-dimensional speckle and tissue Doppler strain measurement during dobutamine stress echocardiography: an angiographic correlation. Eur Heart J. 2007 Jul;28(14):1765-72. https://doi.org/10.1093/eurheartj/ehm188

2. Marcus ML. The coronary circulation in health and disease. McGraw Hill, New York;1983:65-92. 